\title{
Detecting Staphylococcus aureus in milk from dairy cows using sniffer dogs
}

\author{
C. Fischer-Tenhagen, ${ }^{*}$ V. Theby, ${ }^{*}$ V. Krömker, $†$ and W. Heuwieser*1 \\ ${ }^{*}$ Clinic for Animal Reproduction, Faculty of Veterinary Medicine, Freie Universität Berlin, 14163 Berlin, Germany \\ †Department of Bioprocess Engineering-Microbiology, Hannover University of Applied Science and Arts, 30453 Hannover, Germany
}

\begin{abstract}
Fast and accurate identification of disease-causing pathogens is essential for specific antimicrobial therapy in human and veterinary medicine. In these experiments, dogs were trained to identify Staphylococcus aureus and differentiate it from other common mastitis-causing pathogens by smell. Headspaces from agar plates, inoculated raw milk samples, or field samples collected from cows with Staphylococcus aureus and other mastitis-causing pathogens were used for training and testing. The ability to learn the specific odor of Staphylococcus aureus in milk depended on the concentration of the pathogens in the training samples. Sensitivity and specificity for identifying Staphylococcus aureus were 91.3 and $97.9 \%$, respectively, for pathogens grown on agar plates; 83.8 and $98.0 \%$ for pathogens inoculated in raw milk; and 59.0 and $93.2 \%$ for milk samples from mastitic cows. The results of these experiments underline the potential of odor detection as a diagnostic tool for pathogen diagnosis.
\end{abstract}

Key words: mastitis, diagnostic, dogs, volatile organic compounds

\section{INTRODUCTION}

Mastitis is a common and costly disease in dairy industry caused by various infectious pathogens (Harmon, 1994). Treatment protocols for clinical mastitis include local or systemic use of antimicrobials (Barkema et al., 2006). Guidelines for prudent use of antimicrobials advocate an exact, preferably microbiological, diagnosis before treatment (Ungemach et al., 2006; Teale and Moulin, 2012). One disadvantage of treating cows without knowing the exact pathogen involved is that the treatment chosen may not be specific to the causative pathogen, resulting in discarded milk due to treatment, costs incurred due to incorrect treatment, delayed recovery of the cow, and the possibility of in-

\footnotetext{
Received November 6, 2017.

Accepted January 8, 2018.

${ }^{1}$ Corresponding author: w.heuwieser@fu-berlin.de
}

creased antimicrobial resistance due to overuse of an antimicrobials (Cha et al., 2016).

The most used test for bacteriological diagnosis of milk samples is culture of the sample on blood agar plates (Oliver et al., 2004), which takes usually 24 to $48 \mathrm{~h}$. This presents a dilemma to veterinarians who have to treat clinical mastitis in a timely manner and according to the specific pathogen involved. Also, in $30 \%$ of samples from cows with clinical mastitis (Taponen et al., 2009) and in $49.7 \%$ of samples from cows with subclinical mastitis (Makovec and Ruegg, 2003), an infectious agent was not isolated. Furthermore, $40 \%$ of positive cultures involve gram-negative species or yeasts (Lago et al., 2011). For most coliform mastitis, antimicrobial therapy is either not necessary or not worthwhile because of the high self-cure rate (Roberson et al., 2004; Vasquez et al., 2017).

Dating back to 400 BC, Hippocrates recognized the diagnostic value of odors, but the industrial and technological revolution of the 18th and 19th centuries changed the history of medical diagnosis, and odors were neglected in this period (Pavlou and Turner, 2000). More recently, methods such as gas chromatography, mass spectrometry, and electronic nose devices have re-established the value of odors as a potential diagnostic tool. Various infectious agents can be identified by the presence of specific volatile organic compounds (Turner and Magan, 2004; Bruins et al., 2009; Weetjens et al., 2009; Bomers et al., 2012). These technological approaches, however, are cost intensive and require special equipment and expertise.

Animals can be trained to identify and discriminate specific odors (Browne et al., 2006). For rapid diagnosis of tuberculosis, African giant-pouched rats (Crietomys gambianus) were successfully trained to identify Mycobacterium tuberculosis in sputa of patients suspected of having tuberculosis, with a cumulative sensitivity of $86.5 \%$ and specificity of $89.1 \%$ (Weetjens et al., 2009). To identify health-threatening microbial contaminations in hospitals and apartments, dogs have been trained to indicate pathogens such as Streptomyces sp. and Clostridium difficile, respectively (Kauhanen et al., 2002; Bomers et al., 2012). 
The objective of this study was to train dogs to identify Staphylococcus aureus in milk samples from cows with clinical mastitis and to discriminate this pathogen from other relevant mastitis-causing pathogens in dairy cows. Specifically, we set out to demonstrate that (1) dogs can discriminate the odor of Staph. aureus cultivated on blood agar from those of Escherichia coli, Streptococcus uberis, Streptococcus dysgalactiae, Pseudomonas aeruginosa, and Candida albicans; (2) dogs can identify Staph. aureus, Strep. uberis, and Enterococcus inoculated in milk, and (3) dogs can identify Staph. aureus in milk samples from cow with clinical mastitis.

\section{MATERIALS AND METHODS}

Four experiments were conducted to test the hypotheses. In experiment $1, \operatorname{dogs}$ were trained to identify Staph. aureus on agar plates; in experiments 2 and 3, dogs identified Staph. aureus inoculated in milk; and, in experiment 4, dogs identified Staph. aureus in milk samples from cows with clinical mastitis.

\section{Dogs and Handlers}

Nine privately owned dogs of various breeds participated in the experiments of this study (Table 1). Dogs and their owners were recruited on a voluntary basis in a dog training center (Tierakademie Scheuerhof, Wittlich, Germany) as a convenience sample. All dogs were clinically healthy. Dogs and trainers participated in advanced training classes, and 5 dogs had former experience in scent work. According to the German Animal Welfare Bill, no part of the study included harm to any animal.

\section{Bacterial Samples}

Pathogens for training and testing were isolated from milk samples from dairy cows with signs of clinical mastitis; that is, change in milk quality and swelling of the udder. Mastitis samples were sent to a commercial veterinary laboratory (Laboklin $\mathrm{GmbH} \& \mathrm{Co}$. KG, Bad Kissingen, Germany; accreditation number D-Pl-1318601-00). Milk samples were cultivated on Columbia Agar with 5\% sheep blood; Columbia CNA agar, Endo agar, and Saboraud agar with gentamicin and chloramphenicol (all from Becton Dickinson, Heidelberg, Germany). Columbia $5 \%$ blood is not very selective; Pseudomonas spp., Enterobacteriacae, aerobic gram-negative as well as gram-positive pathogens, and yeast can be cultivated; Columbia CNA is selective for gram positive; Endo agar is selective for Enterobacteriaceae and coliforms; and Saboraud agar is selective for fungi (Candida) or dermatophytes. Sampling amount per plate was $10 \mu \mathrm{L}$. Additionally, $1 \mathrm{~mL}$ of milk samples was placed into thioglycolate broth (in-house production) for enrichment. Plates for bacterial culture were incubated at 36 $\pm 1^{\circ} \mathrm{C}$ for 18 to $24 \mathrm{~h}$. Enrichment broth was incubated at $36 \pm 1^{\circ} \mathrm{C}$ for 18 to $24 \mathrm{~h}$ and was then plated on Columbia agar with 5\% sheep blood and Endo agar for a second incubation at $36 \pm 1^{\circ} \mathrm{C}$ for 18 to $24 \mathrm{~h}$. Agar for yeast isolation was incubated at $36 \pm 1^{\circ} \mathrm{C}$. A first reading for yeast growth was done after $48 \mathrm{~h}$ and a final reading after $1 \mathrm{wk}$. After bacteriological growth occurred, pathogens were identified first by colony morphology, Gram strain, and biochemical reactions (catalase, hyaluronidase, oxidase, and esculin reaction). Then, identification was confirmed by matrix-assisted laser desorption/ionization time-of-flight (MALDI-ToF; Shimadzu, Duisburg, Germany; Barreiro et al., 2010). Until use, pathogens were stored at $-20^{\circ} \mathrm{C}$ in cryotubes (Pro-Lab Diagnostics, Richmond Hill, ON, Canada). Bacteria were isolated from 85 milk samples, and we received 35 isolates of Staph. aureus and 10 isolates each of E. coli, Strep. uberis, Strep. dysgalactiae, P. aeruginosa, and C. albicans.

For training and testing, pathogens were cultivated again on Columbia agar with $5 \%$ sheep blood for $24 \mathrm{~h}$ at $36 \pm 1^{\circ} \mathrm{C}$. For early trainings steps, some blank agar plates were placed in the same incubator for the same

Table 1. Dogs included in this study

\begin{tabular}{|c|c|c|c|c|c|c|c|}
\hline \multirow[b]{2}{*}{ Dog } & \multirow[b]{2}{*}{ Breed } & \multirow[b]{2}{*}{ Sex } & \multirow{2}{*}{$\begin{array}{l}\text { Age } \\
(\mathrm{yr})\end{array}$} & \multicolumn{4}{|c|}{ Experiment } \\
\hline & & & & 1 & 2 & 3 & 4 \\
\hline 1 & Jack Russell terrier & Male, intact & 4 & $\mathrm{X}$ & $\mathrm{X}$ & $\mathrm{X}$ & $\mathrm{X}$ \\
\hline 2 & Border collie & Male, intact & 3 & $\mathrm{X}$ & $\mathrm{X}$ & $\mathrm{X}$ & $\mathrm{X}$ \\
\hline 3 & Mix & Male, neutered & 10 & $\mathrm{X}$ & $\mathrm{X}$ & $\mathrm{X}$ & $\mathrm{X}$ \\
\hline 4 & Poodle mix & Male, intact & 2 & $\mathrm{X}$ & & & \\
\hline 5 & Labrador retriever & Male, intact & 2 & $\mathrm{X}$ & & & \\
\hline 6 & Lagotto Romagnolo & Male, neutered & 9 & $\mathrm{X}$ & $\mathrm{X}$ & $\mathrm{X}$ & $\mathrm{X}$ \\
\hline 7 & Lagotto Romagnolo & Male, intact & 9 & $\mathrm{X}$ & $\mathrm{X}$ & $\mathrm{X}$ & $\mathrm{X}$ \\
\hline 8 & Labrador retriever & Male, neutered & 5 & $\mathrm{X}$ & & & \\
\hline 9 & Lagotto Romagnolo & Female, intact & 2 & & & $\mathrm{X}$ & \\
\hline
\end{tabular}


incubation period. Twelve hours before dog training, a sterile cotton swab $(5 \times 5 \mathrm{~cm}$, Fuhrmann Verbandstoffe GmbH, Much, Germany) was placed in the top of the agar plate to absorb the bacterial odor or, for the negative control, the odor of the blank agar plate at $36 \pm 1^{\circ} \mathrm{C}$. The swab had no direct contact with the blood agar. The swabs were then placed in a plastic container (1 L, Jockey Plastik, Wippeführt, Germany) with a perforated lid. To avoid cross contamination, a container was used for one type of pathogen only. For training, the containers including the swab were used for a maximum of 2 wk. Between training sessions, they were kept refrigerated at $6^{\circ} \mathrm{C}$. For $\operatorname{dog}$ testing, new samples were produced by culturing pathogens on blood agar and exposing cotton swabs to the culture odor for $12 \mathrm{~h}$. The swabs were placed into new containers.

For experiment 2, bacterial colonies from same species as in experiment 1 were captured with an inoculation loop from the plate $(1,000 \mathrm{cfu} / \mathrm{mL})$ and dissolved in $2 \mathrm{~mL}$ of fresh bulk tank milk with SCC $<120,000 /$ $\mathrm{mL}$. Of this milk, $1 \mathrm{~mL}$ was pipetted onto a cotton swab and placed in the bottom of the plastic container. In experiments 2 and 3 , bacterial concentrations were $10^{2}$ and $10^{8} \mathrm{cfu} / \mathrm{mL}$, respectively.

Bacterial cell pellets were produced for experiment 3 by incubating 20 strains of Staph. aureus, Strep. uberis, and Enterococcus spp. each (all isolated from milk samples of cows with clinical mastitis) for $24 \mathrm{~h}$ at $36 \pm 1^{\circ} \mathrm{C}$ in $10 \mathrm{~mL}$ of brain-heart broth. From this broth, $100 \mu \mathrm{L}$ was transferred into $10 \mathrm{~mL}$ of sterile brain-heart broth and again incubated at $24 \mathrm{~h}$ at $36 \pm 1^{\circ} \mathrm{C}$ under aerobic conditions. After incubation, $2 \mathrm{~mL}$ of broth of each strain (approximately $2 \times 10^{8} \mathrm{cfu} / \mathrm{mL}$ ) was transferred into a reaction tube (Eppendorf, Wezzlingen-Berzdorf, Germany) and centrifuged $(600 \times g)$ for $15 \mathrm{~min}$. The cell pellet was solved in $100 \mu \mathrm{L}$ of $\mathrm{H}_{2} \mathrm{O}$-free glycerin and the cell glycerin suspension stored in cryotubes at $-20^{\circ} \mathrm{C}$. For dog training and testing, the cell glycerin suspension was solved in $2 \mathrm{~mL}$ of fresh bulk tank milk (SCC $<120,000 / \mathrm{mL}$; total plate count $<10,000 \mathrm{cfu}$ ) and $1 \mathrm{~mL}$ was pipetted on a cotton swab. We used bulk milk instead of sterile milk in order to train the dogs to ignore low concentrations of ubiquitous bacteria. The cotton swabs were placed into plastic containers as described above.

For experiment 4, milk samples from cows with signs of clinical mastitis (see above) were used. Milk sample were sent to the Freie Universität Berlin from various dairy farms in Brandenburg, Germany. Aliquots of 10 $\mathrm{mL}$ were shipped to 3 mastitis diagnostic laboratories and 1 aliquot was refrigerated at $-20^{\circ} \mathrm{C}$. Samples were only included in the experiment if at least 2 laboratories made the same bacteriological diagnosis. Samples with Staph. aureus $(\mathrm{n}=11)$, E. coli $(\mathrm{n}=5)$, Strep. uberis $(\mathrm{n}=8)$, and Trueperella pyogenes $(\mathrm{n}=1)$ were included. For dog testing, $1 \mathrm{~mL}$ of the milk sample was pipetted on a cotton swab and placed into a new plastic container. Up to 10 test samples were generated from 1 aliquot.

\section{Dog Training}

Training was conducted according to a planned training protocol comprising 10 steps (Table 2) under the supervision of a dog trainer, a veterinarian with a postgraduate degree in animal behavior science (V. Theby; www.tierakademie.de). Dogs were trained from May 2012 to February 2013 for experiment 1, from May to July 2014 for experiment 2, and from June to December 2015 for experiment 3. There was no extra training for experiment 4 . The duration of each training step and training progress was documented. Training was based on positive reinforcement, with a clicker as secondary reinforcer and food rewards as primary reinforcer according to Pryor (2009).

\section{Dog Testing}

In experiments 1 and 2 , dogs had to indicate 1 container holding a swab with Staph. aureus odor out of 10 containers holding swabs with odor of 1 of 4 other bacterial species and 1 yeast. The composition of the 9 containers was random. Randomization both for samples within a trial and the order of trials were generated with the random number function of Excel (Microsoft Corp., Redmond, WA).

For experiments 1 and 2, the prevalences of different pathogens within the 10 containers were Staph. aureus (10\%); E. coli (5\%), Strep. uberis (27\%), Strep. dysgalactiae $(28 \%)$, P. aeruginosa $(20 \%)$, and C. albicans $(10 \%)$. Therefore, the chance of identifying the correct container by chance was 1:10. Each dog performed 10 trials with 10 containers each, resulting in 100 samples searched per dog. The protocol was modified for experiment 3. The number of containers was reduced to 7 per trial. Dogs performed 15 trials for a total of 105 samples searched. In experiment 3 , the containers to discriminate were holding swabs with odor of Strep. uberis (23\%), Enterococcus (24\%), or bulk milk without bacteria (39\%). Two trials served as negative controls without a container with Staph. aureus, and 2 trials were done with 2 containers with Staph. aureus. The order of trials was randomized, and the prevalence of Staph. aureus was $15 \%$.

In the fourth experiment, 10 trials were performed with 7 containers each (i.e., total of 70 samples). The 
Table 2. Training protocol in 10 steps to train dogs to discriminate Staphylococcus aureus from other common infectious agents

\begin{tabular}{|c|c|}
\hline Step & Description \\
\hline 3 & $\begin{array}{l}\text { Slowly move container toward floor in } 10-\mathrm{cm} \text { steps and place at different locations on the ground for the dog to touch. Continue } \\
\text { with next step when dog has indicated container on ground with nose with 1-s latency } 10 \text { times out of } 10 \text {. }\end{array}$ \\
\hline 4 & $\begin{array}{l}\text { Add second container without a swab at distance of } 50 \mathrm{~cm} \text {. Ensure that the dog is more likely to reach positive sample first. } \\
\text { Change randomly from left to right. Reward as soon as dog touches positive sample. Repeat } 10 \times \text { before proceeding to next step. }\end{array}$ \\
\hline 5 & $\begin{array}{l}\text { Present both containers next to each other in random order. Reward as soon as dog reaches correct container. Repeat } 10 \times \text { before } \\
\text { proceeding to next step. }\end{array}$ \\
\hline 6 & $\begin{array}{l}\text { Add a third container without a swab in random order. Reward dog when it indicates correct sample for } 3 \mathrm{~s} \text {. Repeat } 10 \times \text { before } \\
\text { proceeding to next step. }\end{array}$ \\
\hline 8 & $\begin{array}{l}\text { Present } 3 \text { containers to discriminate and } 3 \text { positive containers in random order. Dog should indicate positive sample for } 3 \mathrm{~s} \text {. } \\
\text { Repeat } 10 \times \text { before proceeding to next step. }\end{array}$ \\
\hline 9 & Same as step 10, without handler knowing the location of the positive sample. Dog must indicate positive container for $3 \mathrm{~s}$. \\
\hline 10 & Increase number of containers to 10 ( 1 positive and 9 for discrimination) with handler blinded. \\
\hline
\end{tabular}

container to differentiate included Strep. uberis (31\%), Strep. dysgalactiae (3\%), E. coli (10\%), T. pyogenes (2\%), Enterococcus (16\%), and bulk milk (25\%). The prevalence of Staph. aureus in this test was $13 \%$.

Containers were positioned in a circle with a radius of approximately $80 \mathrm{~cm}$, with each container approximately $70 \mathrm{~cm}$ apart. For every trial, unused containers were included. Dogs, handlers, and any other persons in the experimental room were blinded to the position of the sample to avoid hidden clues. The test was videotaped and transferred to another room where the experimenter was seated. Dog handlers were instructed to make sure that the dogs examined every container, even if the dog had already indicated one as being positive. After the dog had searched each container, the dog handler announced the number of the positive container to the experimenter via video transmission. The experimenter gave feedback to the dog handler so that the dog was eventually rewarded. Indications were documented as correct positive, correct negative, false positive, or false negative.

Test characteristics including number of dogs, samples, trials, and odorant used in each experiment are summarized in Table 3.

Table 3. Test characteristics of dogs for detecting Staphylococcus aureus in experiment 1 (blood agar), experiment 2 (inoculated milk, $10^{3} \mathrm{cfu} / \mathrm{mL}$ ), experiment 3 (inoculated milk, $10^{8} \mathrm{cfu} / \mathrm{mL}$ ), and experiment 4 (mastitis milk)

\begin{tabular}{lcccc}
\hline & \multicolumn{4}{c}{ Experiment } \\
\cline { 2 - 5 } Characteristic & \multicolumn{1}{c}{1} & 2 & 3 & 4 \\
\hline Dogs (no.) & 8 & 2 & 6 & 5 \\
Positive:negative containers & $1: 10$ & $1: 10$ & $1: 7$ & $1: 7$ \\
Samples/dog (no.) & 100 & $50-100$ & 105 & 70 \\
Trials (no.) & 10 & $5-10$ & 15 & 10 \\
Correct indications (\%) & 97.2 & 86.6 & 95.9 & 89.4 \\
Sensitivity (\%) & 91.3 & 55 & 83.3 & 59 \\
95\% CI & $83-96$ & $34.2-74.1$ & $74-89$ & $43.4-73.9$ \\
Specificity (\%) & 97.9 & 95 & 98.0 & 93.2 \\
$95 \%$ CI & $96.5-98.7$ & $90.7-97.3$ & $96.1-98.2$ & $89.9-95.5$ \\
\hline
\end{tabular}


Table 4. Test characteristics of sniffer dogs discriminating Staphylococcus aureus from Escherichia coli, Streptococcus uberis, Streptococcus dysgalactiae, Pseudomonas aeruginosa, and Candida albicans (experiment 1)

\begin{tabular}{|c|c|c|c|c|c|c|c|c|c|}
\hline \multirow[b]{2}{*}{ Characteristic } & \multicolumn{9}{|c|}{ Dog } \\
\hline & 1 & 2 & 3 & 4 & 5 & 6 & 7 & 8 & Total \\
\hline Correct negative (no.) & 90 & 88 & 80 & 90 & 90 & 89 & 88 & 90 & 705 \\
\hline False positive (no.) & 0 & 2 & 10 & 0 & 0 & 1 & 2 & 0 & 15 \\
\hline False negative (no.) & 0 & 1 & 3 & 0 & 0 & 1 & 2 & 0 & 7 \\
\hline Sensitivity (\%) & 100 & 90 & 87.5 & 100 & 100 & 90 & 80 & 100 & 91.3 \\
\hline
\end{tabular}

\section{Statistical Analyses}

The analyses were performed with Excel (Office 2010, Microsoft Deutschland GmbH, Munich, Germany) and PASW Statistics for Windows (version 19.0, SPSS Inc., Munich, Germany). Sensitivity and specificity were calculated by using cross tables. Confidence intervals for sensitivity and specificity were calculated with the Wilson score method without continuity correction (Newcombe, 1998). Influences of content of container to discriminate and the individual dog, handler, or trial were calculated with Fisher exact test.

\section{RESULTS}

\section{Required Training Time}

Eight dogs finished the training procedure for experiment 1. Dogs were trained from 27 to 38 training days over 9 mo. The overall training duration (time that dogs worked in training sessions) ranged from 111 to $290 \mathrm{~min}(163.4 \pm 70.2 \mathrm{~min})$. Two dogs were not able to complete the training protocol because they could not progress beyond step 5 in the training protocol. In experiment 2, 5 dogs were trained. Dogs were trained on 17 to $22 \mathrm{~d}$ over 3 mo. Total training time varied from 97 to $191 \mathrm{~min}(154 \pm 35.7 \mathrm{~min})$. Six dogs finished training for experiment 3 . They were trained on 19 to $22 \mathrm{~d}$ over a period of $6 \mathrm{mo}$, with an average training time of 98 to $177 \mathrm{~min}(141.6 \pm 27.5 \mathrm{~min})$. Training time did not differ between the experiments. No additional training was performed for experiment 4 .

\section{Dog Testing}

Sensitivity, specificity, and percentage of correct indications of all dogs for all experiments are summarized in Table 3. Sensitivity and specificity in experiment 1 were $91.3 \%$ (95\% CI: 83-96\%) and 97.9\% (95\% CI: 96.5-98.7\%), respectively. Four dogs did not make any mistakes (i.e., sensitivity and specificity $=100 \%$; Table 4). In experiment 2, 4 dogs showed behavioral signs of stress, such as panting or barking, and were excluded from the test. The 2 remaining dogs completed all 10 trials of experiment 2 (Table 5). Sensitivity and specificity in experiment 2 were $55 \%$ (95\% CI: $34.2-74.1 \%$ ) and $95 \%$ (95\% CI 90.7-97.3\%), respectively. In experiment 3, testing was completed by all 6 dogs trained, and they identified Staph. aureus with a sensitivity and specificity of $83.3 \%$ (95\% CI: $74.0-89.0 \%$ ) and $98 \%$ (95\% CI: 96.1-98.2\%), respectively (Table 6). Five dogs completed experiment 4; test sensitivity was 59\% (95\% CI: $43.4-72.9 \%)$ and specificity was $93.2 \%$ (95\% CI: 89.9-95.5\%) (Table 7). Type of container content to discriminate, or individual dog, handler, or trial had no influence on a false-positive indication.

Table 5. Test characteristics of dogs in experiment 2, identifying Staphylococcus aureus $\left(10^{3} \mathrm{cfu} / \mathrm{mL}\right.$ inoculated in $2 \mathrm{~mL}$ of bulk milk) against Streptococcus uberis and Enterococcus spp. (both $10^{3} \mathrm{cfu} / \mathrm{mL}$ )

\begin{tabular}{|c|c|c|c|c|c|c|}
\hline \multirow[b]{2}{*}{ Characteristic } & \multicolumn{6}{|c|}{ Dog } \\
\hline & 1 & 2 & 4 & 5 & 7 & Total \\
\hline Correct positive (no.) & 6 & -1 & 5 & - & - & 11 \\
\hline Correct negative (no.) & 86 & & 85 & & & 171 \\
\hline False positive (no.) & 4 & & 5 & & & 9 \\
\hline False negative (no.) & 4 & & 5 & & & 9 \\
\hline Sensitivity (\%) & 60 & & 50 & & & 55 \\
\hline Specificity $(\%)$ & 95 & & 94.4 & & & 95 \\
\hline Correct indication (\%) & 92 & & 90 & & & 91 \\
\hline
\end{tabular}


Table 6. Test characteristics of dogs in experiment 3, identifying Staphylococcus aureus $\left(10^{8} \mathrm{cfu} / \mathrm{mL}\right.$ inoculated in $2 \mathrm{~mL}$ of bulk milk) against Streptococcus uberis and Enterococcus spp. (both $10^{8} \mathrm{cfu} / \mathrm{mL}$ )

\begin{tabular}{lccccccc}
\hline & \multicolumn{7}{c}{ Dog } \\
\cline { 2 - 8 } Characteristic & 1 & 2 & 4 & 6 & 8 & 9 & Total \\
\hline Correct positive (no.) & 11 & 13 & 13 & 13 & 14 & 11 & 75 \\
Correct negative (no.) & 88 & 90 & 89 & 86 & 88 & 88 & 529 \\
False positive (no.) & 2 & 0 & 1 & 4 & 2 & 2 & 11 \\
False negative (no.) & 4 & 2 & 2 & 2 & 1 & 4 & 15 \\
Sensitivity (\%) & 73.3 & 86.6 & 86.6 & 86.6 & 93.3 & 73 & 83.3 \\
Specificity (\%) & 97 & 100 & 98.9 & 95 & 97.7 & 97.7 & 98 \\
Correct indication (\%) & 94.3 & 98.1 & 97.1 & 94.3 & 97.1 & 94.3 & 95.9 \\
\hline
\end{tabular}

\section{DISCUSSION}

Four experiments were conducted to study the ability of dogs to identify odors related to Staph. aureus, a relevant mastitis pathogen. In experiment 1 , we demonstrated that dogs can discriminate the odor of Staph. aureus cultivated on blood agar plates from 5 other bacteria and 1 yeast with a sensitivity of $91.3 \%$ and a specificity of $97.9 \%$. Four dogs identified all samples correctly. Lim et al. (2016) used an electronic nose device to identify 15 pathogenic bacterial species by their volatile organic compounds; the sensitivity and specificity of the electronic nose was 91 and $99.4 \%$, respectively. Pathogens produce a specific odor as a result of metabolism of substrates available in growth media (Lough et al., 2017). Our data indicate that dogs could not only identify this odor but also differentiate it from that of other pathogens. Furthermore, this is the first report of dogs being trained to identify the odor of Staph. aureus isolated from mastitis milk samples.

The sensitivity and specificity in experiment 1 were similar to results of a previous study (Johnen et al., 2013), in which dogs differentiated tea against water, which we assume is a relatively easy scent task. Thus, we speculate that Staph. aureus has a distinctive smell that makes it easy for the dog to differentiate it from other pathogens. This is in agreement with the results of Bruins et al. (2009), who identified Staph. aureus strains with a specificity of $88 \%$ using an electronic nose device, and with those of Bomers et al. (2012), who described similar results for detecting Clostridium difficile with a dog.

Milk is a complex matrix comprising a colloid of butterfat, globules, and water with dissolved carbohydrates and protein complexes. The flavoring components vary according to the sample's state such that raw milk elicits a distinct odor (d'Acampora Zellner et al., 2008). It is well known that bacteria grow in and spoil dairy products, which manifests as changes in taste and odor (Bekker et al., 2016). The bacteria are suspended in solution as well as entrapped and absorbed on proteins, micelles, and fat globules (Mortari and Lorenzelli, 2014). In experiments 2 and 3, we tested whether the odor of Staph. aureus changes when inoculated in milk.

In experiment 2, the dogs' detection performance deteriorated. Only 2 of 5 dogs were able to complete all test trials, and the other dogs showed behavioral signs of stress. Scent detection performance of dogs depends on the concentration of the target odor in the sample (Walker et al., 2006). Barkema et al. (1998) considered $100 \mathrm{cfu} / \mathrm{mL}$ of Staph. aureus sufficient to cause an IMI in their study on the incidence of clinical mastitis in dairy herds. Grönlund et al. (2003) found more than $10^{5} \mathrm{cfu} / \mathrm{mL}$ of Staph. aureus in milk samples $24 \mathrm{~h}$ after experimental infection of dairy cows. In experiment 3, the concentration of Staph. aureus was $10^{3} \mathrm{cfu} / \mathrm{mL}$ in

Table 7. Test characteristics of sniffer dogs discriminating Staphylococcus aureus in mastitis milk samples against Streptococcus uberis, Streptococcus dysgalactiae, Trueperella pyogenes, Enterococcus, and Escherichia coli (experiment 4)

\begin{tabular}{lrrrrrr}
\hline & \multicolumn{7}{c}{ Dog } \\
\cline { 2 - 7 } Characteristic & 1 & 2 & 4 & 6 & 8 & Total \\
\hline Correct positive (no.) & 4 & 4 & 6 & 3 & 6 & 23 \\
Correct negative (no.) & 55 & 58 & 58 & 58 & 61 & 290 \\
False positive (no.) & 6 & 5 & 3 & 5 & 2 & 21 \\
False negative (no.) & 5 & 3 & 3 & 4 & 1 & 16 \\
Sensitivity (\%) & 44.4 & 57.1 & 66.7 & 42.9 & 85.7 & 59.0 \\
Specificity (\%) & 90.2 & 87.1 & 95.1 & 92.1 & 96.8 & 93.2 \\
Correct indication (\%) & 84.3 & 88.6 & 91.4 & 87.1 & 95.7 & 89.4 \\
\hline
\end{tabular}


each milk sample, indicating that this bacterial concentration or the volume of $2 \mathrm{~mL}$ was below the detection threshold for the dogs. Therefore, we repeated the experiment with $10^{8} \mathrm{cfu} / \mathrm{mL}$ inoculated in $2 \mathrm{~mL}$ of bulk milk, which allowed all dogs to complete the test trials without signs of stress.

The dogs discriminated Staph. aureus with sensitivity and specificity of 83.3 and $98 \%$, respectively, in experiment 3. To our knowledge, this is the first report to indicate that dogs can be trained to identify Staph. aureus in milk samples. For raw milk samples, only a biosensor for odor detection based on an anti-protein antibody test has been shown to be effective for the detection of Staph. aureus (Esteban-Fernández de Ávila et al., 2012) .

In experiment 4, we tested whether dogs could identify Staph. aureus in milk samples collected from cows with signs of clinical mastitis. Milk samples from mastitic cows and milk samples inoculated with mastitis pathogens differ in composition of volatile organic compounds (i.e., methyl esters of free fatty acids) in the headspace as measured by solid-phase microextraction and GC-MS (Hettinga et al., 2009). In milk samples collected from cows with clinical mastitis caused by Staph. aureus, the sensitivity and specificity of detecting this pathogen were 59 and $93.2 \%$, respectively, which was lower than in experiment 3. One dog, however, identified Staph. aureus with a sensitivity of $85.7 \%$ and a specificity of $96.8 \%$. Inflammation of the udder can lead to considerable changes in milk appearance with flakes, blood, or pus. These components may affect the ability of the dogs to smell the odor of Staph. aureus. We did not conduct specific training for experiment 4 because the number of mastitis samples with matching results from at least 2 laboratories was limited $(\mathrm{n}=$ $25)$. Another limitation was that only samples that had not been used in previous training could be used for testing to avoid the possibility that dogs would remember the odor of individual samples instead of indicating the odor of Staph. aureus (Johnen et al., 2017). It is unclear whether additional training for the detection of Staph. aureus in field cases of mastitis would have improved test characteristics. The good performance of a single dog warrants a larger proof-of-concept study to test this hypothesis.

\section{CONCLUSIONS}

We demonstrated that Staph. aureus emits a specific odor in the headspace of blood agar plates, inoculated milk samples, and milk samples of cows with clinical mastitis. The training and use of sniffer dogs for scent detection in a laboratory is, however, critical for hygiene or as an operating diagnostic tool. Therefore, develop- ing technical solutions such as electronic nose devices as real-time diagnostic methods for mastitis pathogens is considered worthwhile.

\section{ACKNOWLEDGMENTS}

This work was supported by Laboklin GmbH \& Co. KG (Bad Kissingen, Germany). In particular, we want to thank Julia Elze and Babette Klein for a great collaboration and providing us with pathogens. We also thank the dog owners (and their dogs), who did a great job and spent a considerable amount of time on training and participating in this study.

\section{REFERENCES}

Barkema, H. W., Y. Schukken, T. Lam, M. Beiboer, H. Wilmink, G. Benedictus, and A. Brand. 1998. Incidence of clinical mastitis in dairy herds grouped in three categories by bulk milk somatic cell counts. J. Dairy Sci. 81:411-419.

Barkema, H. W., Y. H. Schukken, and R. N. Zadoks. 2006. Invited review: The role of cow, pathogen, and treatment regimen in the therapeutic success of bovine Staphylococcus aureus mastitis. J. Dairy Sci. 89:1877-1895.

Barreiro, J. R., C. R. Ferreira, G. B. Sanvido, M. Kostrzewa, T. Maier, B. Wegemann, V. Böttcher, M. N. Eberlin, and M. V. Dos Santos. 2010. Identification of subclinical cow mastitis pathogens in milk by matrix-assisted laser desorption/ionization time-of-flight mass spectrometry. J. Dairy Sci. 93:5661-5667.

Bekker, A., P. Jooste, L. Steyn, C. Bothma, A. Hugo, and C. Hugo. 2016. Lipid breakdown and sensory analysis of milk inoculated with Chryseobacterium joostei or Pseudomonas fluorescens. Int. Dairy J. 52:101-106.

Bomers, M. K., M. A. van Agtmael, H. Luik, M. C. van Veen, C. M. J. E. Vandenbroucke-Grauls, and Y. M. Smulders. 2012. Using a dog's superior olfactory sensitivity to identify Clostridium difficile in stools and patients: Proof of principle study. BMJ 345:e7396.

Browne, C., K. Stafford, and R. Fordham. 2006. The use of scentdetection dogs. Ir. Vet. J. 59:97-103.

Bruins, M., A. Bos, P. L. Petit, K. Eadie, A. Rog, R. Bos, G. H. van Ramshorst, and A. van Belkum. 2009. Device-independent, realtime identification of bacterial pathogens with a metal oxide-based olfactory sensor. Eur. J. Clin. Microbiol. Infect. Dis. 28:775-780.

Cha, E., R. L. Smith, A. R. Kristensen, J. A. Hertl, Y. H. Schukken, L. W. Tauer, F. L. Welcome, and Y. T. Gröhn. 2016. The value of pathogen information in treating clinical mastitis. J. Dairy Res. 83:456-463.

d'Acampora Zellner, B., P. Dugo, G. Dugo, and L. Mondello. 2008. Gas chromatography-olfactometry in food flavour analysis. J. Chromatogr. A 1186:123-143.

Esteban-Fernández de Ávila, B., M. Pedrero, S. Campuzano, V. Escamilla-Gómez, and J. M. Pingarrón. 2012. Sensitive and rapid amperometric magnetoimmunosensor for the determination of Staphylococcus aureus. Anal. Bioanal. Chem. 403:917-925.

Grönlund, U., C. Hultén, P. D. Eckersall, C. Hogarth, and K. P. Waller. 2003. Haptoglobin and serum amyloid A in milk and serum during acute and chronic experimentally induced Staphylococcus aureus mastitis. J. Dairy Res. 70:379-386.

Harmon, R. J. 1994. Physiology of mastitis and factors affecting somatic cell counts. J. Dairy Sci. 77:2103-2112.

Hettinga, K. A., H. Van Valenberg, T. Lam, and A. Van Hooijdonk. 2009. The origin of the volatile metabolites found in mastitis milk. Vet. Microbiol. 137:384-387.

Johnen, D., W. Heuwieser, and C. Fischer-Tenhagen. 2013. Canine scent detection-Fact or fiction? Appl. Anim. Behav. Sci. 148:201208. 
Johnen, D., W. Heuwieser, and C. Fischer-Tenhagen. 2017. An approach to identify bias in scent detection dog testing. Appl. Anim. Behav. Sci. 98:1-12.

Kauhanen, E., M. Harri, A. Nevalainen, and T. Nevalainen. 2002. Validity of detection of microbial growth in buildings by trained dogs. Environ. Int. 28:153-157.

Lago, A., S. Godden, R. Bey, P. Ruegg, and K. Leslie. 2011. The selective treatment of clinical mastitis based on on-farm culture results: I. Effects on antibiotics use, milk withholding time, and short-term clinical and bacteriological outcomes. J. Dairy Sci. 94:4441-4456.

Lim, S. H., S. Mix, V. Anikst, I. Budvytiene, M. Eiden, Y. Churi, N. Queralto, A. Berliner, R. A. Martino, and P. A. Rhodes. 2016. Bacterial culture detection and identification in blood agar plates with an optoelectronic nose. Analyst 141:918-925.

Lough, F., J. D. Perry, S. P. Stanforth, and J. R. Dean. 2017. Detection of exogenous VOCs as a novel in vitro diagnostic technique for the detection of pathogenic bacteria. Trends Anal. Chem. 87:71-81.

Makovec, J. A., and P. L. Ruegg. 2003. Results of milk samples submitted for microbiological examination in Wisconsin from 1994 to 2001. J. Dairy Sci. 86:3466-3472.

Mortari, A., and L. Lorenzelli. 2014. Recent sensing technologies for pathogen detection in milk: A review. Biosens. Bioelectron. 60:8 21.

Newcombe, R. G. 1998. Two-sided confidence intervals for the single proportion: Comparison of seven methods. Stat. Med. 17:857-872.

Oliver, S., R. Gonzalez, J. Hogan, B. Jayarao, and W. Owens. 2004. Microbiological procedures for the diagnosis of bovine udder infection and determination of milk quality. National Mastitis Council, Verona, WI.

Pavlou, A. K., and A. P. F. Turner. 2000. Sniffing out the truth: Clinical diagnosis using the electronic nose. Clin. Chem. Lab. Med. 38:99-112.
Pryor, K. 2009. Reaching the Animal Mind: Clicker Training and What It Teaches Us About All Animals. Scribner, New York, NY.

Roberson, J. R., L. Warnick, and G. Moore. 2004. Mild to moderate clinical mastitis: Efficacy of intramammary amoxicillin, frequent milk-out, a combined intramammary amoxicillin, and frequent milk-out treatment versus no treatment. J. Dairy Sci. 87:583-592.

Taponen, S., L. Salmikivi, H. Simojoki, M. T. Koskinen, and S. Pyorala. 2009. Real-time polymerase chain reaction-based identification of bacteria in milk samples from bovine clinical mastitis with no growth in conventional culturing. J. Dairy Sci. 92:2610-2617.

Teale, C. J., and G. Moulin. 2012. Prudent use guidelines: A review of existing veterinary guidelines. Rev. Sci. Tech. 31:343-354.

Turner, A. P. F., and N. Magan. 2004. Electronic noses and disease diagnostics. Nat. Rev. Microbiol. 2:161-166.

Ungemach, F. R., D. Mueller-Bahrdt, and G. Abraham. 2006. Guidelines for prudent use of antimicrobials and their implications on antimicrobials usage in veterinary medicine. Int. J. Med. Microbiol. 296:33-38.

Vasquez, A. K., D. V. Nydam, M. B. Capel, S. Eicker, and P. D. Virkler. 2017. Clinical outcome comparison of immediate blanket treatment versus a delayed pathogen-based treatment protocol for clinical mastitis in a New York dairy herd. J. Dairy Sci 100:2992-3003

Walker, D. B., J. C. Walker, P. J. Cavnar, J. L. Taylor, D. H. Pickel, S. B. Hall, and J. C. Suarez. 2006. Naturalistic quantification of canine olfactory sensitivity. Appl. Anim. Behav. Sci. 97:241-254.

Weetjens, B. J., G. F. Mgode, R. S. Machang'u, R. Kazwala, G. Mfinanga, F. Lwilla, C. Cox, M. Jubitana, H. Kanyagha, R. Mtandu A. Kahwa, J. Mwessongo, G. Makingi, S. Mfaume, J. Van Steenberge, N. W. Beyene, M. Billet, and R. Verhagen. 2009. African pouched rats for the detection of pulmonary tuberculosis in sputum samples. Int. J. Tuberc. Lung Dis. 13:737-743. 